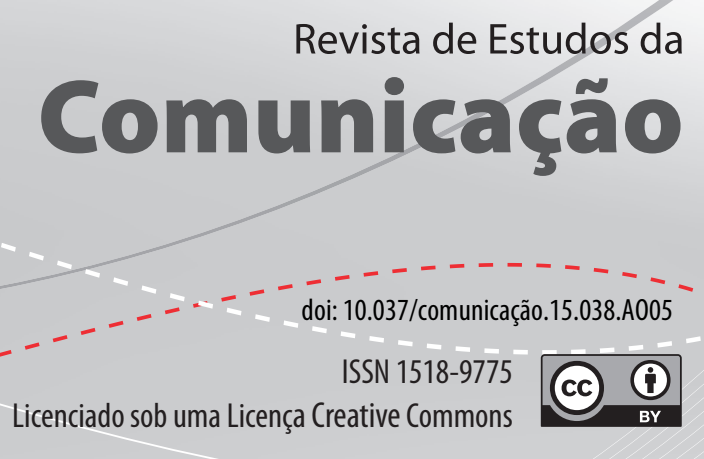

\title{
A Rede de Oposição Radical no Facebook: cartografia e apontamentos sobre os haters políticos ${ }^{1}$
}

The Radical Opposition Network on Facebook: cartography and notes on political haters

\section{Marcelo Alves dos Santos Júnior}

Mestrando do Programa de Pós-Graduação em Comunicação da Universidade Federal Fluminense (UFF), RJ, e-mail: marceloalves.ufsj@hotmail.com

\footnotetext{
Versão ampliada e aprofundada de artigo apresentado no GP Cibercultura, XIV Encontro dos Grupos de Pesquisas em Comunicação, evento componente do XXXVII Congresso Brasileiro de Ciências da Comunicação. O presente trabalho foi realizado com apoio do CNPq, Conselho Nacional de Desenvolvimento Científico e Tecnológico - Brasil.
} 


\section{Resumo}

O espaço conversacional e anônimo das mídias sociais ecoa e torna visível os rastros de grupos de debate e de comentários políticos. Este artigo dedica-se ao mapeamento, cartografia e análise empírica da Rede de Oposição Radical (ROR) no Facebook. O estudo está centrado na formação de grupos na mídia social que reivindicam o espaço discursivo de antagonismo após 12 anos de virada à esquerda no governo brasileiro e da constituição da blogosfera progressiva. Focou-se nas páginas de conteúdo gerado por usuário, a fim de compreender o comportamento do público online como atividade que se assemelha à cultura fã. A ROR atua como comunidade interpretativa polarizada, aproximando usuários a partir de uma lógica antipetista que resgata a importância do partido como atalho balizador do processamento de informações. Os canais promovem o engajamento afetivo dos seguidores por meio da retórica da intransigência e da intolerância dirigidas aos agentes petistas, como um comportamento hater político.

Palavras-chave: Comunicação política. Haters políticos. Antipartidarismo. Mídias Sociais. Cartografia.

\section{Abstract}

The conversational and anonymous space of social media reproduces and gives visibility to traces of debate groups and political commentary. This paper is dedicated to mapping and empirical analysis of the Radical Opposition Network (RON) on Facebook. The study is built on the formation of social media groups that claim the discursive space of antagonism after 12 years of the left turn on the Brazilian government and the constitution of the progressive blogosphere. The focus on the user generated content fan-pages is due to the comprehension of the online individual as an activity resembling the political fandom. The RON acts as polarized interpretive community, connecting individuals through an antipetista logic that reintroduces the party importance as cognitive schema, which guides the information processing. The channels induce the affective engagement followed by the hate and intransigence rhetoric, directed towards the petista agents as a political hater behavior.

Keywords: Political communitcation. Political Haters. Antipartyism. Social Media. Cartography.

\section{Introdução}

Em épocas eleitorais, os sites de mídias sociais se tornam campos de batalha, nos quais grupos rivais se entrincheiram, promovendo discussões agressivas em busca de defender ou de atacar candidatos. Algumas páginas no Facebook se apro- 
ximam de uma postura fundamentalista, elencando inimigos que devem ser destruídos a qualquer custo, o que gera desde críticas construtivas a investidas pessoais, flaming (O'SULLIVAN; FLANAGIN, 2003; GROTE, 2012) e acusações graves à honra. Iniciativa que, não raramente, contribui com a disseminação de boatos, de informações falsas e de hoaxes ${ }^{3}$ (GARRET, 2011). Há pouca literatura disponível sobre movimentos políticos de oposição nas mídias sociais e suas estratégias discursivas. Os canais investigados operam a partir da lógica do enfrentamento e da intolerância contra as minorias, do ordenamento político por meio da repressão e da violência que resulta em um ambiente balcanizado de ciber-ghettos com a função de destruir reputações a qualquer custo (DAHLGREN, 2005; WOJCIESZAC; MUTZ, 2009).

O objetivo deste texto é mapear, cartografar e analisar exploratoriamente a formação, a constituição e as tensões entre grupos oposicionistas que promovem o ódio na circulação de informações e de opiniões políticas. Longe de realizar uma abordagem tecnocentrista, considera-se a articulação dos conteúdos gerados por usuários (VAN DIJCK, 2009) nas redes sociais, enfatizando as fan-pages e a arena de embate que se forma em torno de comunidades interpretativas digitais. A Rede de Oposição Radical é um conjunto de canais que existem e são reconhecidos no Facebook para desmoralizar as ações do Governo Federal por meio de um viés fortemente antipetista, que aciona a retórica da intransigência e da revolta contra as instituições representativas da democracia. Embora a subida no tom e a propaganda negativa sejam utilizadas tanto pela situação, quanto pelo desafiante, o fenômeno aqui investigado indica a articulação de centenas de páginas contra a figura de Dilma Rousseff e do PT, com um público de milhões de fãs, algo inexistente no lado continuísta.

Além disso, este recorte do objeto encontra relevância, considerando o contexto de virada à esquerda dos governos na América Latina (CAMERON, 2009). Após três mandatos presidenciais do Partido dos Trabalhadores (PT), novos agentes assumiram o cenário político do Brasil, em permanente negociação e embate com atores tradicionais. Em meio a esse processo, consolidou-se a blogosfera progressista, ou blogosfera de esquerda, grupo articulado de jornalistas e ativistas que atuam em contraponto à imprensa tradicional (MAGALHÃES; ALBUQUERQUE, 2014). As fan-pages que disseminam a revolta - os reacionários - podem ser interpretadas nesse ecossistema midiático digital como a resposta de grupos conservadores - ainda que menos estruturada e coesa - que ocupa um espaço de debate público e ataque contra as alianças de situação.

\footnotetext{
Flaming é o termo empregado na bibliografia estrangeira para tratar os xingamentos e as acusações dirigidas a personalidades na Internet.

Hoaxes são textos ou propagandas contendo rumores e boatos espalhados sobre candidatos, geralmente, por e-mails e circulares.
} 
Pretende-se, com isso, fornecer pistas para o entendimento das organizações e das manifestações espontâneas de grupos nas redes sociais, assinalando como elas se relacionam ao espectro do ecossistema midiático e político. A investigação lança olhar acerca de quais atores acionam o discurso do ódio, qual seu potencial de influência social, como os temas são abordados, em quais canais e, por fim, realizar uma abordagem da bibliografia da atividade fã, apontando que militantes e simpatizantes se comportam na função de haters políticos. "Estudar os anti-fãs, então, é estudar que expectativas e que valores estruturam o consumo midiático" (GRAY, 2003). Dessa forma, contribui-se para elucidar as disputas simbólicas representadas nas redes entre comunidades de diferentes identidades, que demarcam seu território a ponto de gerar rivalidade recíproca (AMARAL, 2011).

Importante, ainda, pontuar as oportunidades e os limites que as ferramentas de análise de redes sociais oferecem para estudar um ambiente caótico e célere de circulação de dados. Nesse sentido, foi adotada uma perspectiva multimetodológica sequencial, isto é, a cartografia quantitativa da Rede de Oposição Radical (WAICHERT, 2009), seguida de uma abordagem qualitativa guiada pela Teoria Fundamentada, a fim de classificar e categorizar de forma empírica o objeto (FRAGOSO; RECUERO; AMARAL, 2013; HESSE-BIBER; GRIFFIN, 2013). Ao final, são levantadas problematizações quanto à reintrodução do antipartidarismo como atalho cognitivo que enviesa a formação de comunidades interpretativas digitais.

\section{O crescimento da TV Revolta}

Entre abril e maio de 2014, uma página do Facebook chamada TV Revolta despertou a atenção de grande número de usuários, tendo em vista o rápido crescimento de sua audiência e o teor fundamentalista das mensagens. A fan-page adquiriu reconhecimento como fonte de ataques antipetistas dirigidos às lideranças nacionais da sigla e estendidos a toda a sua base aliada. Utilizando-se de memes e de piadas ácidas, o canal recorre à retórica da intransigência para minar a legitimidade das instituições democráticas representativas por meio de um viés antipartidarista e antiesquerdista.

Criada em 2011, a página retrata o personagem João Revolta, interpretado pelo radialista João Almeida Lima. Todavia, apenas em 2014 o canal ganhou relevância, superando a marca de três milhões de fãs - nenhum dos candidatos à presidência havia atingido um milhão até então. Ela se dedica a opinar acerca dos temas nacionais de modo intempestivo e impaciente, utilizando linguagem informal, xingamentos e perpetuando teorias da conspiração que permeiam o senso comum do eleitorado. A intenção, segundo o fundador, é dar voz ao povo e não se ligar a nenhum partido ou interesse econômico "A página nunca apoiou nenhum 
partido, mas é evidente que estamos fazendo uma campanha contra o PT nesse momento já que $99,9 \%$ do nosso público apoia e quer a derrota do PT nas próximas eleições. A insatisfação do povo faz com que tomemos essas ações" ${ }^{4}$.

Foi a página que mais ganhou audiência no Brasil entre os meses de abril e maio, de acordo com levantamento do SocialBakers. No período, teve uma média de 5 a 10 postagens por hora e ganhou em torno de 1,5 milhões de fãs. 0 crescimento sem precedentes foi rapidamente acusado de ser financiado por instituições de oposição ${ }^{5}$, fato negado pelo administrador ${ }^{6}$. o buzz ${ }^{7}$ foi concentrado em poucas semanas. Posteriormente, o aumento de seguidores caiu drasticamente e não voltou a repetir os níveis registrados em abril.

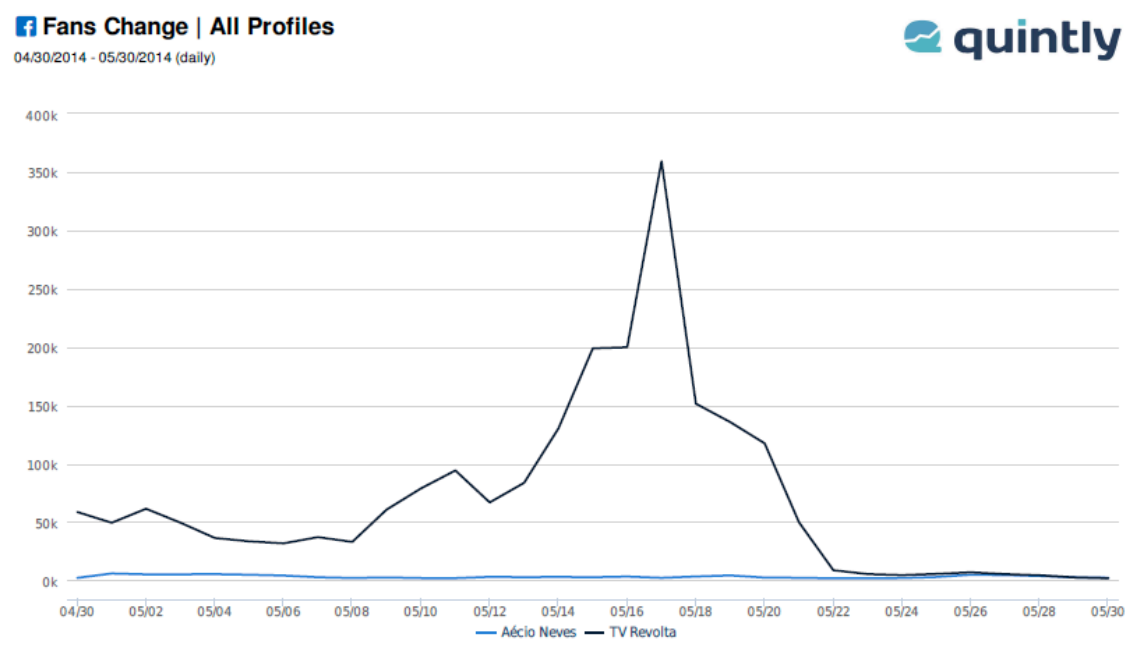

Figura 1 -

Fonte: Quintly.

O padrão encontrado repete-se nas páginas criadas por usuários, que prescindem de estratégia de persuasão em longo prazo. Boa parte surge espontaneamente a partir de assuntos em pauta na mídia e de acontecimentos jocosos,

\footnotetext{
Entrevista cedida ao YouPix, disponível em: <http://youpix.virgula.uol.com.br/pessoas/entrevista-tvrevolta/>.

Disponível em: <http://www.pragmatismopolitico.com.br/2014/05/segredos-tv-revolta.html>. Disponível em: <http://www.folhapolitica.org/2014/05/acusado-de-ser-financiado-por-partidos.html>. Similar ao boca-a-boca, buzz é uma estratégia de marketing digital que faz com que os usuários falem do produto, marca ou candidato.
} 
reapropriando-se de mensagens oficiais de acordo com um contexto particular de significação; caindo em desuso ou esfriando depois que o tema deixa a agenda pública. Isso reflete o ciclo de vida das comunidades digitais, que tendem a ter períodos de nascimento, crescimento, adaptação e morte (VENKATESH, 2003).

Nesse sentido, a TV Revolta aborda variada gama de temas, como o mensalão (exigindo penas severas para os petistas e para Lula); os impostos (acusando o governo de ineficiência nos gastos e desvios de verba pública); o armamento (defendendo o direito de aquisição de armas de fogo e as intervenções ríspidas da Polícia Militar); a mídia (culpando a televisão aberta de manipulação e disseminação de "culturas inúteis"); além de muitos outros tópicos que encontram aprovação em setores conservadores da sociedade brasileira.

No que concerne à linguagem, as postagens adotam tom humorístico, fazendo uso de recursos como o cinismo e o sarcasmo. Isso aproxima os temas da cultura oral e das conversas cotidianas, o que pode ser um caminho profícuo para elucidar o engajamento significativo dos usuários. Os memes transmitidos usam personalidades da política, recorrendo à imagem do então ministro do Superior Tribunal Federal, Joaquim Barbosa, como "caçador de corruptos". De fato, a fan-page o alça ao patamar de herói da nação e pede sua eleição como presidente do país.

As críticas são voltadas quase que exclusivamente ao PT e à sua base de aliança governista, sendo que é inexistente o antagonismo a instituições partidárias de direita, apesar de reivindicar a representação da voz do povo, recurso discursivo empregado por diversos órgãos de mídia populistas. A configuração do público da TV Revolta, porém, é de jovens, majoritariamente do estado de São Paulo, o que aponta o lugar de fala como representativo de parte da juventude do sudeste do país que não se sente contemplada pelas ações do PT e reage com agressões simbólicas nas redes sociais.

\section{Cartografia da Rede de Oposição Radical (ROR)}

O fenômeno da vertiginosa expansão do público da TV Revolta levantou o questionamento: existem outras páginas de retórica similar contra o Governo Federal e contra as ideologias identificadas como de esquerda? Quem são estes atores? Quais estratégias empregam? Como se articulam? Para tentar responder a estas perguntas, empregou-se o Quintly como mecanismo de auxílio nas buscas pelas páginas que são geradas por usuários que atacam agressivamente os agentes de situação política. Este ponto é sedimentado pelo olhar qualitativo, avaliando um a um os canais mais movimentados que possuam postagens que, em geral, mobili- 
zam um sentimento de revolta contra o estado e seus órgãos de representação democrática.

Esse trabalho identificou dezenas de páginas que se encaixavam no tema proposto no artigo. Entende-se que o objeto ia muito além da TV Revolta como mobilizadora de um discurso reacionário de ódio político. Filtrou-se o ranking pelo número de perfis falando sobre a página, isto é, a quantidade de interações recentes. Assim, encontram-se os hubs de informação mais ativos: com considerável número de postagens e participação dos usuários. Sem contar a TV Revolta, foram encontrados diversos outros canais de discurso oposicionista radical, com destaque para o Movimento Contra a Corrupção (MCC) e a Folha Política.

Tabela 1 - Monitoramento de canais

\begin{tabular}{|c|c|c|c|c|c|}
\hline \multicolumn{7}{c|}{ Monitoramento Canais Ódio-Oposição } \\
\hline Página & & & & \\
\hline Movimento Contra Corrupção & Likes & Cidade & Início & Público & Falando sobre \\
\hline TV Revolta & 1350433 & São Paulo & 2012 & $18-34$ & 651400 \\
\hline OCC - Organização de Combate à Corrupção & 3668291 & São Paulo & 2010 & $18-24$ & 552000 \\
\hline Juventude Contra a Corrupção & 179133 & São Paulo & 05.06 .2012 & $25-34$ & 71200 \\
\hline Canal da Direita & 72546 & São Paulo & 02.04 .2013 & $18-24$ & 69800 \\
\hline Folha Política & 113790 & São Paulo & 15.05 .2013 & $18-34$ & 69500 \\
\hline Dilma sem voto & 628600 & São Paulo & Maio de 2013 & $25-34$ & 62900 \\
\hline Bolsonaro Zuero 3.0 & 42519 & São Paulo & 24.06 .2014 & $18-24$ & 55428 \\
\hline Dilma Ralada & 106722 & São Paulo & 14.11 .2013 & $18-24$ & 41900 \\
\hline Libertroll & 4087 & São Paulo & 21.05 .2014 & $25-34$ & 38700 \\
\hline Politicamente Irado & 22446 & São Paulo & 17.01 .2013 & $18-24$ & 30300 \\
\hline Dilma Rousseff, NÃO & 21284 & São Paulo & 12.08 .2013 & $25-44$ & 29700 \\
\hline Política na Rede & 78054 & São Paulo & 07.12 .2012 & $25-34$ & 25600 \\
\hline Fora PT & 246461 & São Paulo & 08.06 .2013 & $25-34$ & 22600 \\
\hline Gu era esquerdista mas a zuera me curou 1.0 & 268714 & São Paulo & 27.10 .2011 & $25-34$ & 21400 \\
\hline Gazeta Social & 53019 & São Paulo & 27.11 .2013 & $18-24$ & 11900 \\
\hline & 109166 & São Paulo & 30.08 .2013 & $18-34$ & 11000 \\
\hline
\end{tabular}

Fonte: Autor, 2014.

O MCC articula uma rede de nós espalhada por diversos estados e cidades, bem como seguidores como a Organização Contra a Corrupção (OCC) e a Juventude Contra a Corrupção. As postagens, em geral, acusam o Governo Federal de práticas indevidas, roubo, improbidade e crimes, frequentemente usando linguagem agressiva. Os alvos escolhidos são a presidente, Dilma Rousseff (PT), o expresidente Luiz Inácio Lula da Silva (PT) e os acusados do mensalão; com referências esparsas aos senadores Fernando Collor (PTB-AL) e José Sarney (PMDB-MA).

O núcleo da Folha Política funciona como fonte principal de informações de grande parte das páginas da lista de influenciadores do discurso do ódio. A fanpage no Facebook possui mais de 620 mil curtidas e se dedica ao compartilhamen- 
to de notícias de seu site. O portal reivindica o título de jornalismo independente, não obstante, reúna múltiplas matérias curtas de propaganda negativa contra o governo. O Canal da Direita, a Política na Rede, a Gazeta Social e a Folha do Povo destinam-se apenas a reproduzir os textos da Folha Política, aumentando sua audiência e atingindo outros nichos.

Com a lista pronta, foi utilizado o crawler Netvizz para extrair as informações de todas as ligações manifestas pelas páginas, gerando a cartografia de páginas de oposição (RIEDER, 2013). Os dados foram coletados durante o mês de julho de 2014. $O$ resultado, contudo, ainda teve de ser filtrado para excluir todas as entradas que não se relacionavam com o tema do artigo. Devido à natureza dinâmica e orgânica das mídias sociais, ressalva-se que o panorama pode ser alterado com o passar do tempo ou com a inserção de novos temas na agenda nacional.

A informação foi processada utilizando os seguintes algoritmos do Gephi: (1) modularidade: identifica grupos de nós que compartilham conexões entre suas arestas e os reúnem em comunidades; (2) autoridade: mede fatores que determinam a relevância de nós no ambiente (3) hubs: grupos de nós que possuem alta densidade de ligações; e (4) outdegree: quantidade total de menções que um nó recebeu, isto é, quantas páginas se ligam a ele (VALDEZ et al., 2012).

Com isso, utilizou-se o layout Force Atlas 2 para produzir a visualização do grafo, organizado de acordo com os algoritmos escolhidos, e possibilitar a interpretação. O Force Atlas 2 é um modelo de espacialização baseado nas leis da gravidade: os nós produzem força de repulsão entre si, enquanto que as arestas os aproximam. A gravidade atrai os nós para o centro e espalha os hubs pela periferia (JACOMY et al., 2011). Com isso, pode-se identificar quais páginas são mais influentes, como estão interconectadas e quais são as principais comunidades.

A cartografia da Rede de Oposição Radical (ROR) no Facebook representa as ligações entre centenas de páginas que têm como objetivo criticar e atacar o Governo Federal e a base de aliança de situação do PT. Entre os canais levantados, percebem-se diferenças relativas à abordagem, aos propósitos ideológicos e ao tom utilizado no tratamento e na produção das mensagens. Enfatiza-se que o mapeamento não tem a presunção de fornecer um relatório completo de todas as fan-pages que se mobilizam e que representam o desencanto com a política. Ao contrário, o ecossistema orgânico e complexo das redes dificulta tal tarefa. Por isso, o grafo apresentado tem a função de guiar as questões e gerar o panorama dos relacionamentos que se hierarquizam na rede. Cabe ressaltar que não somente a oposição emprega o discurso do ódio, o recurso é posto em ação por diversos agentes, dependendo do contexto político-eleitoral. 


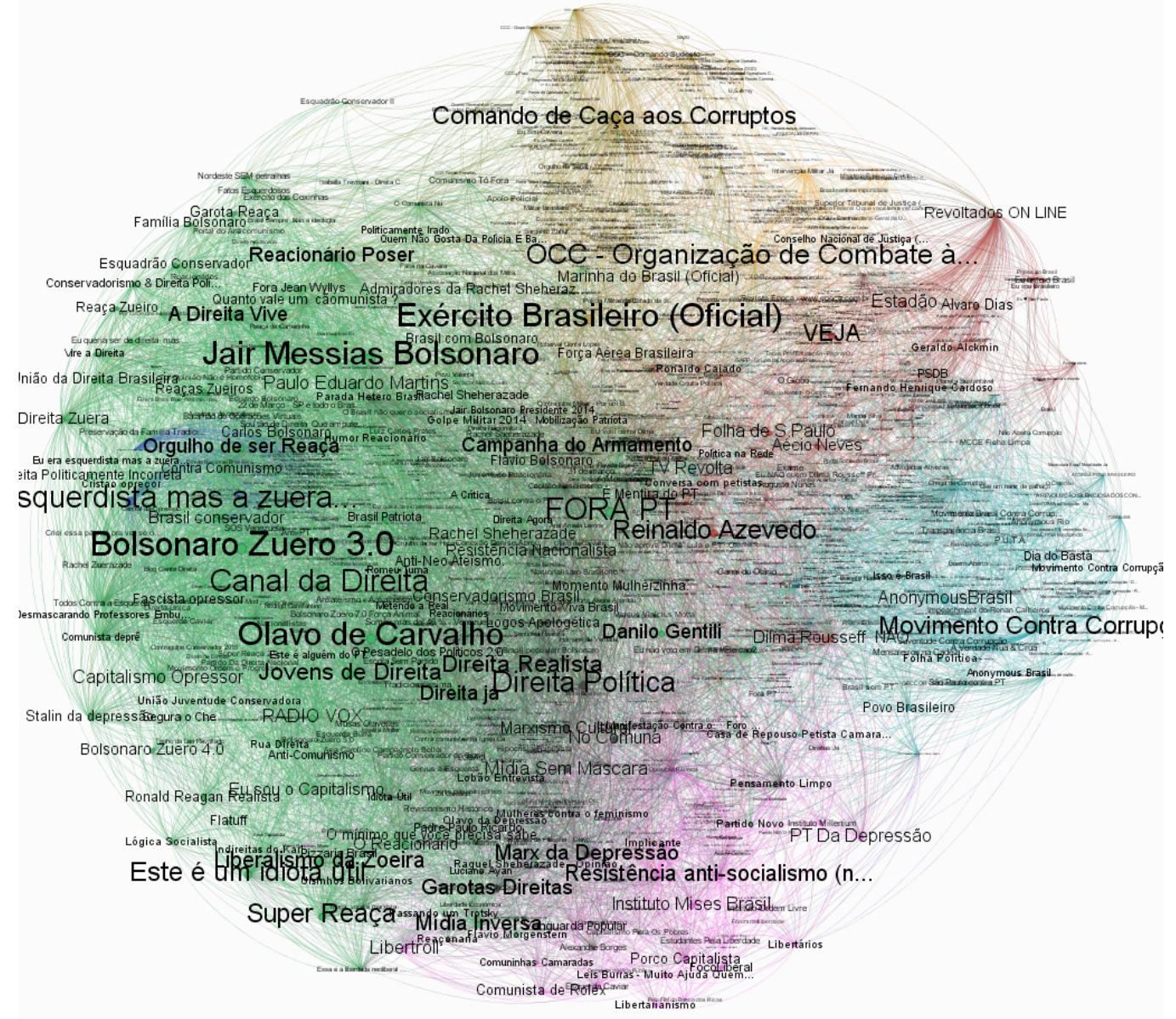

Figura 2 -

Fonte: Autor, 2014.

Seguindo a perspectiva metodológia da Teoria Fundamentada, buscou-se reunir e classificar empiricamente os dados coletados. Com isso, foram identificados cinco subgrupos majoritários na cartografia. Assim, a partir de dados quantitativos relativos à densidade de ligações entre os nós e uma investigação qualitativa do conteúdo disseminado em cada hub, indica-se uma tipologia baseada nos diferentes discursos acionados por cada comunidade.

(1) Moralista e militarista: no topo, em laranja e amarelo, está o hub que possui duas páginas ao centro: Comando de Caça aos Corruptos e Organização de 
Combate à Corrupção. Ao redor, há diversos canais que se ligam a setores militares (Intervenção Militar Já; Orgulho de Servir, Eu sou Caveira) e ao judiciário (Brasil contra a Impunidade; Brasil contra a Corrupção). A comunidade defende o moralismo político, acusando o Governo Federal e sua base de aliança de corrupção. Pode-se afirmar que seja um grupo orientado pelo uso da retórica do ódio para denegrir a imagem do bloco de situação, sem problematizar a ideia de corrupção e manifestando-se a favor do aumento da força policial e militar.

(2) Fontes de informação: a parte em vermelho possui fan-pages oficiais de meios de comunicação, Veja, Estadão, Exame, O Globo e Folha de S. Paulo; do PSDB e políticos como Geraldo Alckmin, Fernando Henrique Cardoso, Ronaldo Caiado e Aécio Neves; bem como os colunistas Reinaldo Azevedo e Ricardo Noblat. Já que nenhuma delas foi utilizada como grau de saída, conclui-se que estejam ilustradas no grafo a partir de arestas de saída dos demais nós, representando fonte de informação ou referência ideológica.

(3) Guerra àcorrupção: em azul, outro hub orientado contra a corrupção, encabeçado pelo Movimento Contra a Corrupção e suas secções estatais. As arestas apontam para nós como: Juventude Contra a Corrupção, Povo Brasileiro, Chega de Corruptos, Isso é Brasil, Dia do Basta, Mensaleiros na Cadeia e Anonymous Brasil, Transparência Brasil e o Partido Novo. Mais ao centro, estão TV Revolta e Política na Rede.

(4) Liberal e anticomunista: em roxo na parte sul, está um grupo declarado liberal e anticomunista. Entre os principais canais, ressaltam-se: Resistência antisocialismo (nazismo, comunismo e outras doutrinas vermelhas), Libertarianismo, Libertários, Foco Liberal, Marx da Depressão, PT da Depressão, Porco Capitalista, Mulheres Contra o Feminismo, Manifestação Contra o Foro de São Paulo, Comunista de Rolex e Esquerda Caviar.

(5) Reacionários e cínicos: a grande comunidade verde se divide entre canais reacionários de direita, apoiadores do deputado federal, Jair Messias Bolsonaro (PP-RJ), e humoristas. Notam-se Canal da Direita, Direita Já, Direita Política, Bolsonaro Zuero 3.0, Jovens de Direita, Super Reaça, a Direita Vive, Fora PT, Anti neo-ateísmo, Resistência Nacionalista, Esquadrão Conservador e Politicamente Irado. Ademais três páginas oficiais estão localizadas mais ao centro do hub, Olavo de Carvalho, Paulo Eduardo Martins e Rachel Sheherazarde. Pelo acentuado número de arestas, são canais de considerável influência entre os nós próximos, até com fã clubes destinados a repercutir suas mensagens, como Admiradores de Rachel Sheherazarde e Musas Olavettes.

A cartografia indica que a Rede de Oposição Radical se organiza de forma orgânica, descentralizada, fragmentária e sem proposta de ação em longo prazo. Em comum, os canais reivindicam um espaço discursivo de oposição com a finalidade de eliminar os agentes petistas do Governo Federal. A retórica do grupo 
assume tons agressivos, ora apelando para o sentimento de revolta, ora atacando a corrupção, indicando uma política de visibilidade sustentada pelos sentimentos de frustração e cinismo. As mensagens, então, adotam estratégia de caracterizar as lideranças dos partidos da base governista como inimigos que devem ser derrotados a qualquer custo. Os temas abordados são muito variados, como moralismo, corrupção, militarismo e justiça, reforçando a cultura da violência e da repressão no embate contra as minorias.

Há a presença do que pode ser considerada como a velha extrema-direita, fazendo referências ao integralismo, ao nacionalismo e ao exército, e características emergentes configuradas no ecossistema particular das redes digitais (BARBOSA, 2008). O grupo se opõe claramente às ações que considera neonazistas e neofacistas, por considerar resquícios do comunismo e do socialismo. Contudo, nos fluxos performáticos de oposição nas mídias digitais, também se encontra a preocupação em se desvencilhar da conotação histórica negativa da direita brasileira, sendo que são raros os canais que apoiam abertamente a volta do governo militar.

A rede de páginas de oposição no Facebook não se preocupa em definir filiação partidária. Algumas comunidades se destinam ao apoio a candidatos como Jair Bolsonaro, mas, em geral, dispensam estruturas partidárias e não fazem campanha aberta a nenhum candidato à presidência do Brasil. É o discurso do ódio e da revolta contra a situação que as une. Levando em consideração os apontamentos de Comparato (2014), nenhum partido atualmente fomenta esses sentimentos de ódio, até porque a legislação eleitoral brasileira dificulta a ascensão de novos agentes ao poder. Contudo, enfatiza-se, seguindo Norris (2005), que as alterações na opinião pública pressionam as bases oposicionistas a modificar suas propostas. Essa configuração dinâmica do mercado eleitoral carrega potencial de tornar os programas mais conservadores.

\section{Discussão teórica}

A Rede de Oposição Radical possui mais de mil canais, alguns com grande repercussão, como a TV Revolta, o Movimento Contra a Corrupção, Fora PT, a Organização Contra a Corrupção, Movimento Brasil Consciente, Revoltados Online e o Bolsonaro Zuero 3.0, e outros que atendem a um público de nicho e têm características diversas, por vezes, contraditórias. Contudo, eles partilham o sentimento de exclusão das instâncias tradicionais de tomada de decisão e a abordagem cínica, fundamentalista e pessimista, com estratégia retórica que apela para as emoções, para o humor e para o envolvimento com a política no mundo da vida cotidiana. Embora boa parte das fan-pages investigadas renegue afiliações partidárias, pode- 
se localizar um conteúdo ideológico que flerta com elementos conservadores e reacionários, sem a preocupação de definir uma linha clara de propostas.

Nesse sentido, argumenta-se que, no contexto sociopolítico contemporâneo brasileiro, em que a confiança nas instituições representativas se mostra em declínio e as preferências ideológicas clássicas parecem cada vez menos relevantes na tomada de posição eleitoral, a as siglas ainda se mostram atalhos cognitivos que balizam significativamente as ideias que as pessoas formulam dos candidatos e do governo (SAMUELS; ZUCCO, 2014). Isso acontece porque as manifestações textuais encontradas na rede de páginas de oposição são notadamente direcionadas pelo quadro de abordagem antipetista, reproduzindo uma identificação partidária negativa que tende a ditar o tom de boa parte das perspectivas interpretativas empregadas pelas fan-pages (MEDEIROS; NOEL, 2013). Ou seja, há uma reintrodução da lógica partidária, que regula práticas interpretativas em comunidades digitais, por meio de circuitos difusos de antagonismo e de conflito.

Além do ataque ao governo, relacionado a agentes políticos petistas, os canais empreendem críticas que visam à desconstrução das ideias e das propostas consideradas de esquerda e, hiperbolicamente, identificadas como socialistas, comunistas e bolivarianas. Esse procedimento aciona quatro campos valorativos: (1) elementos de classe, adotando ofensivas elitistas contra a ignorância do povo na escolha de seus representantes; (2) aspectos capitalistas, no que concerne aos conteúdos programáticos econômicos; (3) moralistas, que defendem a tradição da família e dos bons costumes; e (4) político-ideológicos, que se opõem declaradamente a todas as instituições e doutrinas classificadas como de esquerda.

Assim, entende-se que existem fluxos políticos antipartidários e antipolíticos em um ambiente não-institucional e caótico, no qual atores anônimos se mobilizam pontualmente na proposição de agendas de ataque ao governo petista. Para isso, problematiza-se como definir a gama de páginas que se mobilizam de modo pouco ordenado contra as ideologias de esquerda, sobretudo o socialismo e o comunismo. Entende-se que sejam metamorfoses de um discurso ambivalente que, embora não se autodenomine de direita entre todos os agentes, simbolize reconfigurações de matizes e de valores conservadores de direita que retomam nuances das expressões políticas do mundo da vida cotidiana (BASINGER; LAVINE, 2005).

Por isso, a ROR atua como comunidade interpretativa polarizada, aproximando indivíduos com pensamentos similares em subgrupos no formato de canais do Facebook (FISH, 1980). A formação das identidades coletivas que unem os seguidores destes canais se dá a partir da exclusão de elementos considerados hiperbolicamente como representantes da esquerda comunista, corrupta e ditatorial, representada, sobretudo, na figura do PT (MOUFFE, 2005). Essa retórica da intransigência e do preconceito antipetista disseminada pelas mensagens e memes das páginas e ratificada pelos fãs nos comentários sugere a reintrodução do partido 
como atalho cognitivo que baliza a formação de opiniões sobre o governo, os candidatos e as ações políticas (LODGE; HAMIL, 1986; RAHN, 1993; DESART, 1995).

Ademais, pode-se fazer referência à bibliografia da atividade fandom, mais especificamente aos trabalhos que tratam dos fãs políticos para dar conta do engajamento afetivo dos seguidores com o conteúdo das fan-pages (WRIGHT, 2011; SANDVOSS, 2012; SANDVOSS, 2013). Tendo isso em mente, indica-se que a ROR representa um comportamento hater político que se manifesta na organização coletiva de agentes que externam profundo escárnio e ressentimento contra o PT, nem sempre se preocupando em definir alguma alternativa partidária, mas alçando os petistas a inimigos ferrenhos da nação que devem ser destruídos a qualquer preço. É um posicionamento que aciona o caráter performático das identificações políticas nas mídias sociais, orientado para a negação de tudo o que se julga representar como petista (MONTARDO; ARAÚJO, 2013).

\section{Conclusões}

Este trabalho buscou conceituar a Rede de Oposição Radical como um conjunto de páginas que surgem e são reconhecidas no Facebook como fonte de ataques agressivos ao Governo Federal e suas instituições representativas, a partir da lógica do antipartidarismo e, sobretudo, do antipetismo. O ecossistema das redes sociais é célere e efêmero, dificultando a apreensão completa do comportamento dos agentes e da circulação das mensagens. Ainda assim, foram utilizadas técnicas da Análise de Redes Sociais para traçar a cartografia das ligações entre os canais, indicando a atuação dos subgrupos temáticos militarista, anticomunista, moralista, reacionário, fontes de informação e líderes de opinião.

Em seguida, a partir da Teoria Fundamentada, buscou-se classificar e analisar empiricamente o fenômeno, seguindo o estudo das mensagens divulgadas pelas páginas à luz de teorias da comunicação, dos estudos sobre a atividade fã e da ciência política. Nesse sentido, a ROR representa comunidades interpretativas que são guiadas pelo engajamento afetivo de haters políticos de identidades coletivas que se definem pela exclusão de elementos da esquerda, assumindo posição antipartidária e antipetista. Isso indica a reintrodução da lógica partidária como quadro que orienta as opiniões dos eleitores sobre os candidatos e sobre os temas políticos nacionais.

Ao mesmo tempo, a arena de disputa simbólica e de debates políticos nas mídias sociais levanta múltiplos questionamentos que não foram aprofundados neste artigo. Assim, investigações posteriores devem levar adiante a ideia de polarização das redes sociais digitais e do antagonismo como fenômeno que acontece em um campo de força, no qual acionamentos discursivos competem hierarquica- 
mente por um regime de verdade. Ainda, a ideia de reintrodução da lógica partidária nas comunidades interpretativas é interessante, na medida em que acontece em consonância com a queda e a fragmentação da preferência por siglas políticas específicas, apontando para uma reconfiguração da comunicação política que considera as formações ideológicas de modo mais fluido, perso-nalizado e cotidiano.

\section{Referências}

AMARAL, A. Redes sociais, linguagem e disputas simbólicas. ComCiência, n. 131, 2011.

BASINGER, S. J.; LAVINE, H. Ambivalence, information, and electoral choice. American Political Science Review, v. 99, n. 2, p. 169-184, 2005.

BASTIAN, M.; HEYMANN, S.; JACOMY, J. Gephi: an open source software for exploring and manipulating networks. ICWSM, v. 8, p. 361-362, 2009.

CAMERON, M., Latin America's Left Turns: beyond good and bad, Third World Quarterly, v. 30, n. 2, p. 331-348, 2009.

COMPARATO, B. K. Uma Direita Radical no Brasil? Comunicação apresentada no IX Encontro da ABCP, Brasília/DF, 2014.

DAHLGREN, P. The Internet, public spheres, and political communication: Dispersion and deliberation. Political Communication, v. 22, p. 147-62, 2005.

DESART, J. A. Information processing and partisan neutrality: A reexamination of the party decline thesis. The Journal of Politics, v. 57, n. 3, p. 776-795, 1995.

$\mathrm{FISH}, \mathrm{S}$. E. Is there a text in this class?: The authority of interpretive communities. Harvard University Press, 1980.

FRAGOSO, S.; RECUERO, R.; AMARAL, A., Métodos de pesquisa para internet, Porto Alegre: Sulina, 2013.

GARRETT, R. K. Troubling consequences of online political rumoring. Human Communication Research, v. 31, p. 255-274, 2011.

GRAY, J. New Audiences, New Textualities Anti-Fans and Non-Fans. In: International Journal of Cultural Studies, v. 6, n. 1, 2003, p. 64-81.

GROTE, A. S. Flaming on Facebook. Dissertação apresentada na Faculdade de Ciências Behaviouristas, Programa de Fatores Humanos e Psicologia Humana da Universidade de Twente, 2012. 
HESSE-BIBER, S.; GRIFFIN, A. Internet-Mediated Technologies and Mixed Methods Research: Problems and Prospects. Journal of Mixed Methods Research, v. 7, p. 43-62, 2012.

JACOMY, M. et al. A Graph Layout Algorithm for Handy Network Visualization. 29 ago. 2011. Disponível em: <http://webatlas.fr/tempshare/ForceAtlas2_Paper.pdf>. Acesso em: 20 de jul. de 2014.

LODGE, M.; HAMILL, R. A partisan schema for political information processing. The American Political Science Review, v. 80, n. 2, p. 505-520, 1986.

MAGALHÃES, E.; AlBUQUERQUE, A. Jornalistas sem jornal: a blogosfera progressista no Brasil; In: Anais do XXIII Encontro Anual da Compós, Belém/PA, 2014.

MEDEIROS, M.; NOEL, A. The Forgotten Side of Partisanship Negative Party Identification in Four Anglo-American Democracies. Comparative Political Studies, v. 47, n. 7, p. 1022-1046, 2013.

MONTARDO, S. P.; ARAÚJO, W. Performance e práticas de consumo online: ciberativismo em sites de redes sociais. Revista FAMECOS: mídia, cultura e tecnologia, v. 20, n. 2, p. 472-494, 2013.

NORRIS, P. Radical Right: voters and parties in the electoral market. Cambridge: Cambridge University Press, 2005.

O'SULLIVAN, P.; FLANAGIN, A., Reconceptualizing 'flaming' and other problematic messages. New Media \& Society, v. 5, n. 1, p. 69-94, 2003.

RAHN, W. M. The role of partisan stereotypes in information processing about political candidates. American Journal of Political Science, v. 37, n. 2, p. 472-496, 1993.

RIEDER, B. Studying Facebook via data extraction: the Netvizz application. Proceedings of the 5th Annual ACM Web Science Conference. ACM, 2013.

SAMUELS, D.; ZUCO, C. The Power of Partisanship in Brazil: Evidence from Survey Experiments. American Journal of Political Science, v. 58, n. 1, p. 212-225, 2014.

SANDVOSS, C. Enthusiasm, trust and its erosion in mediated politics: On fans of Obama and the Liberal Democrats. European Journal of Communication, v. 27, n. 1, p. 68-81, 2012.

SANDVOSS, C. Toward an understanding of political enthusiasm as media fandom: Blogging, fan productivity and affect in American politics, Journal of Audience \& Reception Studies, v. 10, n. 1, 2013. 
VALDEZ, A. C., et al. Using mixed node publication network graphs for analyzing success in interdisciplinary teams. Active Media Technology. Springer Berlin Heidelberg, p. 606-617, 2012.

VAN DIJCK, J. Users like you? Theorizing agency in user-generated content. Media Culture Society, v. 31; p. 41-58, 2009.

VAN ZOONEN, L. Imagining the fan democracy. European Journal of Communication, v. 19, n. 1, p. 39-52, 2004.

VENKATESH, M. The Community Network Lifecycle: A Framework for Research and Action Special Issue: ICTs and Community Networking. The Information Society, v. 19, n. 5, p. $339-347,2003$.

WAICHERT, T. Cartografias da Blogosfera: uma abordagem sobre a produção de sociabilidade, linguagem e subjetividade nos blogs, Trabalho de Conclusão de Curso. Universidade Federal do Espírito Santo, 2009.

WOJCIESZAK, M.; MUTZ, D. Online Groups and Political Discourse: Do Online Discussion Spaces Facilitate Exposure to Political Disagreement?, Journal of Communication, v. 59, p. 40-56, 2009.

WRIGHT, J. The Obama Haters: behind the right-wing campaign of lies, innuendo and racism. Washington: Potomac Books, 2011.

Recebido: $19 / 10 / 2014$

Received: $10 / 19 / 2014$

Aprovado: 20/11/2014

Approved: $11 / 20 / 2014$ 